\title{
Comparability of blue shark mortality estimates for the Atlantic and Pacific longline fisheries
}

\author{
Steven E. Campana ${ }^{1, *}$, Warren Joyce ${ }^{1}$, Malcolm P. Francis ${ }^{2}$, Michael J. Manning ${ }^{2, \mp}$ \\ ${ }^{1}$ Bedford Institute of Oceanography, PO Box 1006, Dartmouth, Nova Scotia, Canada B2Y 4A2 \\ ${ }^{2}$ National Institute of Water and Atmospheric Research (NIWA), Private Bag 14901, Kilbirnie, Wellington, New Zealand
}

\begin{abstract}
Blue sharks Prionace glauca are among the most frequently caught and discarded fish species in pelagic longline fisheries of both the Atlantic and Pacific oceans. Fishery-specific differences between Atlantic and Pacific longliners lead to differences in both hooking and post-release mortality rates. However, the estimates of both hooking and post-release mortality reported by Moyes et al. (2006; Trans Am Fish Soc 135:1389-1397) around Hawaii are considerably lower than those reported elsewhere, both in the Atlantic and the Pacific. Our comparison of Campana et al. (2009; Mar Ecol Prog Ser 387:241-253) with Moyes et al. suggests that the difference in blue shark mortality estimates is explained by the partial use of $\mathrm{J}$ hooks in the Atlantic fishery, and by the shorter soak time, fewer hooks fished, and gentler handling practices by the scientific crew in the Pacific study by Moyes et al. The study by Moyes et al. is an important contribution to our understanding of blue shark mortality; nevertheless, we consider it inappropriate to use their low estimates of blue shark mortality as a proxy for bycatch mortality rates in the commercial fishery.
\end{abstract}

KEY WORDS: Pop-up satellite archival tag $\cdot$ Hooking mortality $\cdot$ Soak time Discard mortality · Longline fishery

\section{Introduction}

Blue sharks Prionace glauca are among the most frequently caught fish species in pelagic longline fisheries of both the Atlantic and Pacific oceans. Due both to their low commercial value (leading to discarding) and their relative abundance, estimates of capture and post-release mortality are important prerequisites of any population model attempting to estimate blue shark population health and sustainable levels of fishing effort. Several studies have documented capture (hooking) mortality in North Atlantic pelagic longline fisheries (Diaz \& Serafy 2005, Kerstetter \& Graves 2006, ICCAT 2008, Campana et al. 2009, Carruthers et al. 2009) and in the Pacific Ocean (Francis et al. 2004, Moyes et al. 2006, Yokota et al. 2006, Walsh et al. 2009). However, only 1 study in each ocean has at- tempted to estimate post-release mortality (Moyes et al. 2006, Campana et al. 2009). While the Moyes et al. study is an important and well-executed contribution to our understanding of blue shark mortality in the Pacific around Hawaii, their estimates of both hooking and post-release mortality are considerably lower than those reported elsewhere, including elsewhere in the Pacific. Musyl et al. (2009) suggest that this difference reflects real differences between the Atlantic and Pacific commercial fisheries. If true, this would suggest that commercial pelagic longline fishing in the Pacific is having a relatively small effect on blue shark survival. We argue, however, that bycatch mortality in the Pacific is likely higher than reported by Moyes et al. (2006) and Musyl et al. (2009), despite the likelihood of fishery-specific differences between the Atlantic and Pacific regions. Given that the study designs of Moyes 
et al. (2006) and Campana et al. (2009) share a number of commonalities, we suggest that a comparable study carried out on Pacific commercial pelagic longliners, rather than a research vessel, would be likely to produce mortality estimates that are more representative of the Pacific fishery.

To explain the different mortality results for the Atlantic and Pacific studies, 2 questions must be answered: (1) How representative are the 2 studies of their respective commercial fisheries? (2) How similar are the Atlantic and Pacific pelagic longline fisheries to each other? We suggest that there are probably real differences in fishery practices between Atlantic and Pacific pelagic longline fisheries, which contribute to mortality differences, but that those differences were artifactually exaggerated by the study design of Moyes et al. (2006).

\section{Mortality differences between studies}

\section{Hooking mortality}

There is a broad range of hooking mortality rates reported for blue sharks, with the possibility of higher mortalities in North Atlantic pelagic longline fisheries compared to those of the Pacific. However, such differences in mortality do not explain the very low rates reported by Moyes et al. (2006). In the North Atlantic, hooking mortality rates have averaged 15 to $20 \%$, including rates of 12 to $20 \%$ in the Canadian fishery (Campana et al. 2009), 18 to $22 \%$ for the USA fishery (ICCAT 2008, their Table 2.4), and 31\% for certain components of the USA fishery (Diaz \& Serafy 2005). Kerstetter \& Graves (2006) reported that mortality rates in the USA fishery differed with hook type: $7.4 \%$ on circle hooks and $22.8 \%$ on J hooks. The Atlantic mortality rates were slightly higher than the 5 to $18 \%$ range reported for the pelagic longline fishery off New Zealand, where the mean value depended on the year, fishery and fleet $(18,13,10$ and $10 \%$ for the Japanese north and south, and domestic New Zealand north and south fleets, respectively, prior to 2000, and 6, 8, 14 and $5 \%$ mortality more recently) (Ayers et al. 2004, Francis et al. 2004, Griggs et al. 2007, 2008). Hooking mortality rates varied between 2 and $11 \%$ in the Japanese tuna fishery (Yokota et al. 2006). Walsh et al. (2009) reported a minimum mortality of 4 to $8.5 \%$ in the Hawaii-based longline fishery, with the $8.5 \%$ value reflecting shallow-water sets more characteristic of swordfishing. In contrast, Moyes et al. did not report any dead sharks whatsoever; their value of $5 \%$ represented moribund sharks only. Considering that none of the other studies included moribund or lethargic sharks in their dead category, this comparison indicates that the scientific fishing used to collect shark samples in Moyes et al. somehow resulted in fewer deaths and serious injuries than reported elsewhere.

There are several possible explanations for the differences in hooking mortality rates between fisheries and/or scientific studies. Musyl et al. (2009) were correct to point out that only circle hooks were used in the Moyes et al. (2006) study, whereas a combination of circle and $\mathrm{J}$ hooks were used in the fishery monitored by Campana et al. (2009) — circle hooks have been documented as producing a lower hooking mortality in blue sharks compared to J hooks (Kerstetter \& Graves 2006, Carruthers et al. 2009). However, the difference in hook types cannot explain all, or even most, of the mortality rate differences between the 2 studies; only $9 \%$ of the hooks used in the tagging trips of Campana et al. were $\mathrm{J}$ hooks. In addition, hooking mortality rates of 17 to $27 \%$ were reported on trips where only circle hooks were used (Campana et al. 2009, their Table 2).

Musyl et al. (2009) also considered the possibility of size-selective mortality on the hook. In both the Moyes and Campana studies, however, the mean length of the blue sharks which were tagged was similar to that in the local fishery (165 to $170 \mathrm{~cm}$ fork length). Thus it seems unlikely that size differences contributed to mortality rate differences between the Atlantic and the Pacific fisheries.

The most likely explanation of the observed mortality rate difference is the relatively short soak time and low hook number of the gear used in the Moyes et al. (2006) study. Longer soak time leads to higher hooking mortality in most fish species, including blue sharks (Ward et al. 2004, Campana et al. 2009, Carruthers et al. 2009). Moyes et al. reported a mean soak time of about $12 \mathrm{~h}$, which is substantially less than the $18 \mathrm{~h}$ characteristic of the Atlantic fishery (Campana et al. 2009) and the mean of $21 \mathrm{~h}$ characteristic of the Pacific fishery (Ward et al. 2004). The difference in soak time is at least partially due to the difference in the number of hooks deployed, and the time required to bring them aboard: Moyes et al. fished with only 400 to 600 hooks per set, while both Atlantic and Pacific pelagic longliners usually deploy more than twice as many. Ward et al. (2004) reported that the distant-water longliners in the Pacific averaged about 3000 hooks per operation, with a mean soak time of $22 \mathrm{~h}$, while even the shortduration fresh-chilled longliners averaged 1000 hooks with a mean soak time of $20 \mathrm{~h}$. Referring specifically to the swordfishery around and north of the Hawaiian Islands, Ward et al. (2004) reported a mean set duration of $22 \mathrm{~h}$, and 812 hooks per set. Atlantic pelagic longliners deploy between 500 and 1700 hooks per set, with an overall mean of about 1100 hooks. Therefore, the zero hooking mortality rate reported by Moyes et al. was probably due at least in part to a fishing strat- 
egy (low hook number and reduced soak time) which enhanced blue shark survival and did not reflect the practices of either the Hawaiian or (more broadly) other Pacific commercial fisheries.

Finally, the hooking mortality estimate by Moyes et al. (2006) was based on the examination of only 172 blue sharks. Based on binomial uncertainty alone, it would be very difficult statistically to differentiate their estimate of $0 \%$ dead and $5 \%$ moribund from one of $10 \%$ mortality; the large variability due to among-set and among-vessel effects could double that uncertainty.

\section{Handling and tagging mortality}

Musyl et al. (2009) suggested that the handling associated with the application of pop-up satellite archival tags (PSATs) may have increased the probability of blue shark mortality, but we consider this to be unlikely. In both the Moyes et al. (2006) and Campana et al. (2009) studies, scientific handling was relatively gentle and required less than 10 min per shark. We have never observed death in an uninjured shark after only 10 min on deck, and indeed, have seen instances of blue sharks actively moving on decks after more than $1 \mathrm{~h}$ out of the water. Since trauma associated with hooking is the major source of post-release mortality (Campana et al. 2009), we do not consider that the scientific component of the handling unduly affected the results of either study.

While the tagging procedure did not appear to affect mortality, the same cannot be said of the handling of blue sharks by the crew of a commercial fishing boat. Musyl et al. (2009) noted that blue sharks discarded as part of the Hawaii-based commercial fishery are generally not brought aboard, but cut off at the line. The same is practised in the Atlantic fishery - fishermen do not waste time bringing non-target species aboard. However, they will sometimes attempt to remove hooks from jaw-hooked sharks as the gangion is brought up to the rail, if they think that they can do so quickly and easily. This practice can lead to trauma, and thus a higher risk of mortality (Campana et al. 2009). Given the cost of hooks, we would be very surprised if Hawaii-based fishermen did not do the same on occasion. A commercial fishing crew in either ocean will not be nearly as concerned about the well-being of a 'trash fish' such as a blue shark as would a scientific fishing crew, and will certainly not use a sling to bring a shark up to the rail before cutting the gangion. As a result, handling mortality of a discarded fish species is inevitably higher aboard a commercial boat than on a scientific vessel. While quantification of commercial discard mortality was a stated objective of Campana et al. (2009), it was not a stated objective of Moyes et al. Therefore, the use of scientific fishing did not reduce the scientific value of the Moyes et al. study, but it does imply that their results cannot be used to estimate commercial discard mortality.

\section{Finning}

One aspect of fishing mortality not quantified in either the Atlantic or Pacific studies is that of finning (the practice of cutting off the fins of sharks and discarding the carcass at sea), which should result in $100 \%$ discard mortality (although small blue sharks are sometimes not finned, and may be discarded whole). Finning was banned by most nations in the North Atlantic beginning in the 1990s, culminating in a 2004 ban by the International Commission for the Conservation of Atlantic Tunas (ICCAT), the agency responsible for high seas fisheries in the Atlantic. The Inter-American Tropical Tuna Commission (IATTC), responsible for high seas fisheries in the eastern Pacific Ocean, banned finning in 2005. These resolutions are not enforced, and finning continues to be practised (legally or illegally) by some nations in both oceans, but there are no reliable estimates of its extent. However, fin sales in the Hong Kong market greatly exceed globally reported shark landings, suggesting that finning is a major cause of shark mortality in both the Atlantic and Pacific Oceans (Clarke et al. 2006).

\section{Post-release mortality}

Post-release mortality of uninjured, discarded blue sharks should not differ between the Atlantic and the Pacific fisheries. Moyes et al. (2006) applied PSATs only to healthy sharks, and observed $100 \%$ survival. Campana et al. (2009) observed identical results in the healthy sharks that they tagged with PSATs. Therefore, the 2 studies are entirely consistent in terms of post-release mortality rates of healthy sharks. The difference between the studies is that the Atlantic study also tagged injured sharks and observed $33 \%$ mortality in those individuals. No corresponding estimates are available for the Pacific fishery.

The factor contributing the most to the large discrepancy in overall bycatch mortality rates between the Atlantic and the Pacific fisheries is the injury rate associated with capture, leading to post-release mortality. Moyes et al. (2006) classified all of their moribund sharks (5\% of the total) as dead, which implied that none of the remainder were injured. In contrast, Campana et al. (2009) reported an injury rate of $44 \%$ (above and beyond the hooking mortality) in their tag- 
ging trips, and $31 \%$ in the trips monitored by observers. The term injury is a relative term, and was not standardized between the studies, but there appears to be a very large difference between the study results, which strongly affects any estimates of overall postrelease mortality. Apparently, some aspect of fishing practice differed substantially between the Atlantic commercial and the Pacific scientific fishing enterprise, leading to trauma in Atlantic blue sharks, but not in the scientifically-fished Pacific sharks. And since only the sharks with serious trauma subsequently died after release, the difference in injury rates would explain most of the inter-ocean difference in overall bycatch mortality.

\section{Future research}

The biochemical proxies of stress advocated by Moyes et al. (2006) and Musyl et al. (2009) are unlikely to prove effective as independent measures of postrelease mortality until further studies using pop-up satellite archival tags (PSATs) are completed. While we agree that biochemical indices do indeed have promise as measures of stress, it is post-release mortality that is of interest, not stress. How can correlates of stress be used to predict mortality without independent information on the fate of the stressed shark? And how can the fate of the released shark be assessed other than through PSATs? Moyes et al. only tagged and sampled 1 blue shark which subsequently died, which is a very low sample size for a meaningful measure of postrelease mortality. The biochemical approach will be valid and useful after it has been calibrated on a larger sample of PSAT-tagged sharks, and after all contributing factors (such as water temperature and whether or not the shark swallowed the hook) have been assessed. This work remains to be done.

\section{Conclusions}

Fishery-specific differences between Atlantic and Pacific pelagic longliners probably result in differences in both hooking and post-release mortality between the 2 fisheries. However, our comparison of the Moyes et al. (2006) and Campana et al. (2009) studies suggests that any real differences are confounded by the partial use of $\mathrm{J}$ hooks in the Atlantic fishery, and by the shorter soak time, fewer hooks, and gentler handling practices by the scientific crew in Moyes et al.
The study design of Moyes et al. by no means reduces its considerable scientific value, but we consider it inappropriate to use their results as a proxy for commercial bycatch mortality rates in the Pacific pelagic longline fishery.

\section{LITERATURE CITED}

Ayers D, Francis MP, Griggs LH, Baird SJ (2004) Fish bycatch in New Zealand tuna longline fisheries, 2000-01 and 200102. New Zealand fisheries assessment report No. 2004/46, Ministry of Fisheries, Wellington

Campana SE, Joyce W, Manning MJ (2009) Bycatch and discard mortality in commercially caught blue sharks Prionace glauca assessed using archival satellite pop-up tags. Mar Ecol Prog Ser 387:241-253

Carruthers EH, Schneider DC, Neilson JD (2009) Estimating the odds of survival and identifying mitigation opportunities for common bycatch in pelagic longline fisheries. Biol Conserv 142:2620-2630

Clarke SC, McAllister MK, Milner-Gulland EJ, Kirkwood GP and others (2006) Global estimates of shark catches using trade records from commercial markets. Ecol Lett 9: 1115-1126

Diaz GA, Serafy JE (2005) Longline-caught blue shark (Prionace glauca): factors affecting the numbers available for live release. Fish Bull 103:720-724

Francis MP, Griggs LH, Baird SJ (2004) Fish bycatch in New Zealand tuna longline fisheries, 1998-99 to 1999-2000. New Zealand fisheries assessment report No. 2004/22, Ministry of Fisheries, Wellington.

Griggs LH, Baird SJ, Francis MP (2007) Fish bycatch in New Zealand tuna longline fisheries $2002-03$ to $2004-05$. New Zealand fisheries assessment report No. 2007/18, Ministry of Fisheries, Wellington.

Griggs LH, Baird SJ, Francis MP (2008) Fish bycatch in New Zealand tuna longline fisheries in 2005-06. New Zealand fisheries assessment report No. 2008/27, Ministry of Fisheries, Wellington.

ICCAT (2008) Report of the 2008 shark stock assessments meeting. ICCAT SCRS/2008/017. International Commission for the Conservation of Atlantic Tunas, Madrid.

Kerstetter DW, Graves JE (2006) Effects of circle versus Jstyle hooks on target and non-target species in a pelagic longline fishery. Fish Res 80:239-250

> Moyes CD, Fragoso N, Musyl MK, Brill RW (2006) Predicting postrelease survival in large pelagic fish. Trans Am Fish Soc 135:1389-1397

> Musyl MK, Moyes CD, Brill RW, Fragoso NM (2009) Factors influencing mortality estimates in post-release survival studies: Comment on Campana et al. (2009). Mar Ecol Prog Ser 396:157-159

Walsh WA, Bigelow KA, Sender KL (2009) Decreases in shark catches and mortality in the Hawaii-based longline fishery as documented by fisheries observers. Mar Coast Fish 1: 270-282

Ward P, Myers RA, Blanchard W (2004) Fish lost at sea: the effect of soak time on pelagic longline catches. Fish Bull 102:179-195

> Yokota K, Kiyota M, Minami H (2006) Shark catch in a pelagic longline fishery: comparison of circle and tuna hooks. Fish Res 81:337-341

Submitted: November 17, 2009; Accepted: November 24, 2009 Proofs received from author(s): November 25, 2009 